\title{
Buoyancy-Induced Convection in Water From a Pair of Horizontal Heated Cylinders Enclosed in a Square Cooled Cavity
}

Marta Cianfrini, Massimo Corcione, Luca Cretara, Massimo Frullini, Emanuele Habib, Pawel Oclon, Alessandro Quintino, Vincenzo Andrea Spena \& Andrea Vallati

To cite this article: Marta Cianfrini, Massimo Corcione, Luca Cretara, Massimo Frullini, Emanuele Habib, Pawel Oclon, Alessandro Quintino, Vincenzo Andrea Spena \& Andrea Vallati (2021) Buoyancy-Induced Convection in Water From a Pair of Horizontal Heated Cylinders Enclosed in a Square Cooled Cavity, Heat Transfer Engineering, 42:3-4, 205-214, DOI: 10.1080/01457632.2019.1699289

To link to this article: https://doi.org/10.1080/01457632.2019.1699289

Published online: 10 Dec 2019.

Submit your article to this journal

山 Article views: 73

Q View related articles ๘

View Crossmark data $\asymp$ 


\title{
Buoyancy-Induced Convection in Water From a Pair of Horizontal Heated Cylinders Enclosed in a Square Cooled Cavity
}

\author{
Marta Cianfrini ${ }^{a}$, Massimo Corcione ${ }^{b, c}$, Luca Cretara $^{b}$, Massimo Frullini $^{b}$, Emanuele Habib ${ }^{b}$, Pawel Oclon ${ }^{d}$, \\ Alessandro Quintino ${ }^{\mathrm{b}, \mathrm{c}}$, Vincenzo Andrea Spena ${ }^{\mathrm{b}}$, and Andrea Vallati ${ }^{\mathrm{b}}$ \\ ${ }^{a}$ DIMI, Università degli Studi Roma Tre, Rome, Italy; ${ }^{b}$ DIAEE Sezione Fisica Tecnica, Sapienza Università di Roma, Rome, Italy; ${ }^{c}$ INFN, \\ Sezione di Roma La Sapienza, Rome, Italy; 'Institute of Thermal Power Engineering, Cracow University of Technology, Kraków, Poland
}

\begin{abstract}
Buoyancy-driven convention from a pair of horizontal heated cylinders, set side by side inside a square cooled cavity filled with water, is studied numerically. The system of the conservation equations of mass, momentum and energy expressed in dimensionless form is solved through a control-volume formulation of the finite-difference method. The pressurevelocity coupling is handled using the SIMPLE-C algorithm. Numerical simulations are executed for different values of the Rayleigh number based on the cylinder diameter, as well as the width of the cavity, the inter-cylinder spacing and the distance of the cylinders from the bottom wall of the cavity normalized by the cylinder diameter. Two heat and fluid flow configurations are generally found to establish inside the cavity, according as the cylinders are located at close distance or at such a distance that the effects of the lateral walls of the cavity become important, each of these configurations being distinguished by the existence of an optimum inter-cylinder spacing which maximizes the overall heat transfer rate. Moreover, when the inter-cylinder spacing is such that the cylinders are located sufficiently close to the cavity sides, a periodic flow arises.
\end{abstract}

\section{Introduction}

Free convection heat transfer from heated horizontal cylinders set side by side inside enclosures filled with water has a considerable relevance to several engineering applications, e.g., heat exchangers, energy storage devices, and electronic components. The first welldocumented study performed on this topic was executed by Incropera and Yaghoubi [1] using water tanks with the top open to room air, in which a swaying motion of the thermal plumes rising above the submerged cylinders was observed. Plume oscillations were also detected by Kuehner et al. [2] for a single submerged cylinder, and by Fiscaletti et al. [3] for a single cylinder suspended inside a closed cavity cooled at the walls. Besides a number of further studies dealing with vertically-aligned cylinders [4-9] or staggered cylinders $[10,11]$ or side-by-side differentially heated cylinders [12-14], just marginally related to the present investigation, no other study expressly dedicated to free convection in liquids from confined cylinders is readily available in the literature, which implies a significant shortness of data for this configuration.

For this reason, a numerical study on natural convection from a pair of heated horizontal cylinders set side by side in a water-filled square enclosure cooled at the four boundary walls is performed, with the main scope to evaluate in what measure the imposed temperature difference, the cavity size, and the location and spacing of the cylinders, affect the overall heat transfer performance, as well as to discuss the basic heat and fluid flow features.

\section{Analysis and modeling \\ Mathematical formulation}

A water-filled square enclosure of width $\mathrm{W}$, containing a pair of horizontal cylinders of radius $\mathrm{R}$, is considered. The cylinders, set side by side at a center-to-center distance $\mathrm{L}$, with their axes located at a distance $\mathrm{H}$ from the bottom of the enclosure, are heated at a uniform temperature $t_{h}$, while the four boundary walls of the

CONTACT Professor Massimo Corcione massimo.corcione@uniroma1.it $@$ DIAEE Sezione Fisica Tecnica, Sapienza Università di Roma, via Eudossiana 18, 00184 Rome, Italy.

Color versions of one or more of the figures in the article can be found online at www.tandfonline.com/uhte.

(C) 2019 Taylor \& Francis Group, LLC 


\section{Nomenclature}

cylinder diameter, $\mathrm{m}$

dimensionless frequency of oscillation

gravity vector, $\mathrm{m} / \mathrm{s}^{2}$

gravity acceleration, $\mathrm{m} / \mathrm{s}^{2}$

distance of the cylinder axis from the bottom of the cavity, $\mathrm{m}$

inter-cylinder spacing, $\mathrm{m}$

Nusselt number

dimensionless pressure

Prandtl number

cylinder radius, $\mathrm{m}$

dimensionless radial coordinate

Rayleigh number

dimensionless temperature

temperature, $\mathrm{K}$

dimensionless velocity vector, $\mathrm{m} / \mathrm{s}$

width of cavity, $\mathrm{m}$

\section{Greek symbols}

$\alpha \quad$ thermal diffusivity, $\mathrm{m}^{2} / \mathrm{s}$

$\beta \quad$ coefficient of volumetric thermal expansion, $1 / \mathrm{K}$

$\theta \quad$ dimensionless polar coordinate

$\nu \quad$ kinematic viscosity, $\mathrm{m}^{2} / \mathrm{s}$

$\rho \quad$ mass density, $\mathrm{kg} / \mathrm{m}^{3}$

$\tau \quad$ dimensionless time

$\Omega \quad$ dimensionless period of oscillation

Subscripts

c cooled wall, at the temperature of the cooled walls

$\mathrm{h}$ heated cylinder, at the temperature of the heated cylinders

i i-th heated cylinder $(i=1,2)$

max maximum value

min minimum value cavity are cooled at a uniform temperature $t_{c}$, as sketched in Figure 1. The resulting buoyancy-induced flow is considered to be two-dimensional, laminar and incompressible, with constant physical properties. The buoyancy effects on the momentum transfer are taken into account through the customary Boussinesq approximation. Viscous dissipation and pressure work, as well as radiative heat transfer, are neglected.

Upon incorporating these hypotheses into the equations of continuity, momentum and energy, the following set of governing equations expressed in dimensionless form is obtained:

$$
\begin{gathered}
\nabla \cdot \mathbf{V}=0 \\
\frac{\partial \mathbf{V}}{\partial \tau}+(\mathbf{V} \cdot \nabla) \mathbf{V}=-\nabla \mathrm{P}+\nabla^{2} \mathbf{V}-\frac{\mathrm{Ra}}{\operatorname{Pr}} \mathrm{T} \frac{\mathbf{g}}{\mathrm{g}} \\
\frac{\partial \mathrm{T}}{\partial \tau}+(\mathbf{V} \cdot \nabla) \mathrm{T}=\frac{1}{\operatorname{Pr}} \nabla^{2} \mathrm{~T}
\end{gathered}
$$

where $\tau$ is the dimensionless time normalized by $\mathrm{D}^{2} /$ $\nu, \mathbf{V}$ is the dimensionless velocity vector normalized by $\nu / \mathrm{D}, \mathrm{T}$ is the dimensionless temperature excess over the uniform temperature of the cavity walls normalized by the temperature difference $\left(t_{h}-t_{c}\right), P$ is the dimensionless sum of the thermodynamic and hydrostatic pressures normalized by $\rho \nu^{2} / \mathrm{D}^{2}, \mathbf{g}$ is the gravity vector, $\mathrm{g}$ is the gravity acceleration, $\mathrm{Pr}=\nu / \alpha$ is the Prandtl number set to 7 (corresponding to water at a temperature of $293 \mathrm{~K}$ ), and $\mathrm{Ra}$ is the Rayleigh number defined as

$$
R a=\frac{g \beta\left(t_{h}-t_{c}\right) D^{3}}{\alpha \nu}
$$

in which $\mathrm{D}=2 \mathrm{R}$ is the cylinder diameter, $\nu$ is the kinematic viscosity, $\rho$ is the mass density, $\alpha$ is the

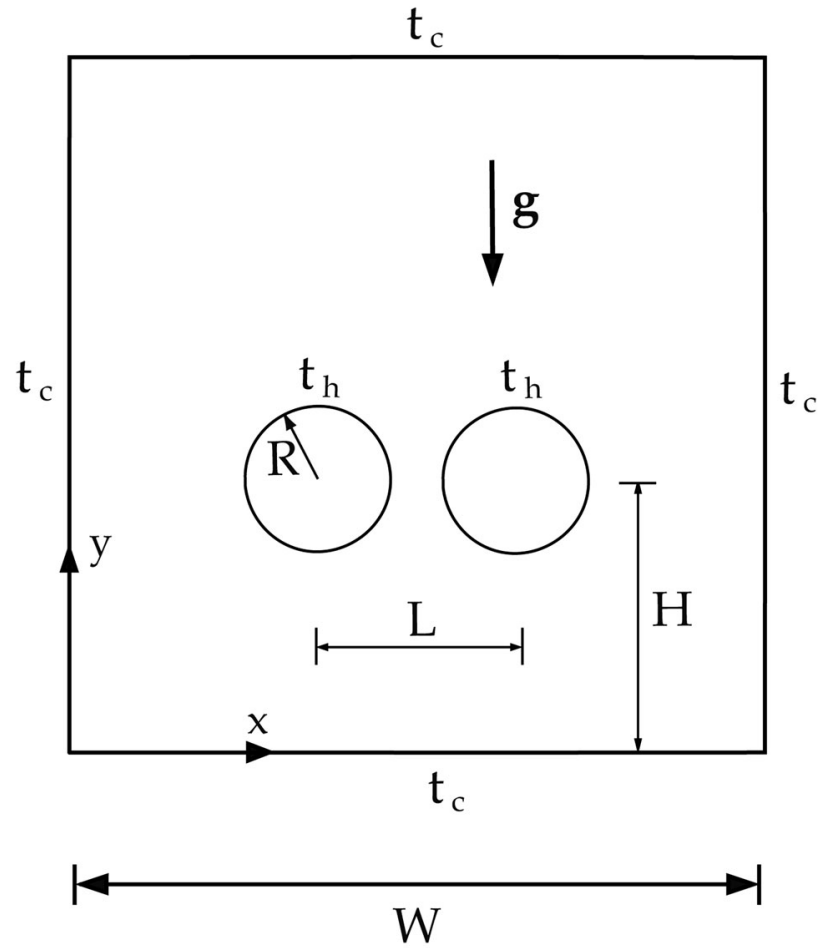

Figure 1. Sketch of the geometry and boundary conditions.

thermal diffusivity, and $\beta$ is the coefficient of volumetric thermal expansion.

The assigned boundary conditions are: (a) $\mathrm{T}=1$ and $\mathbf{V}=0$ at the surface of the heated cylinders; and (b) $\mathrm{T}=0$ and $\mathbf{V}=0$ at the four cavity walls. The initial conditions assumed throughout the enclosure are fluid at rest, i.e., $\mathbf{V}=0$, and uniform temperature $\mathrm{T}=0$.

\section{Computational procedure}

The system of the governing equations defined by Eqs. (1)-(3), in combination with the boundary and 


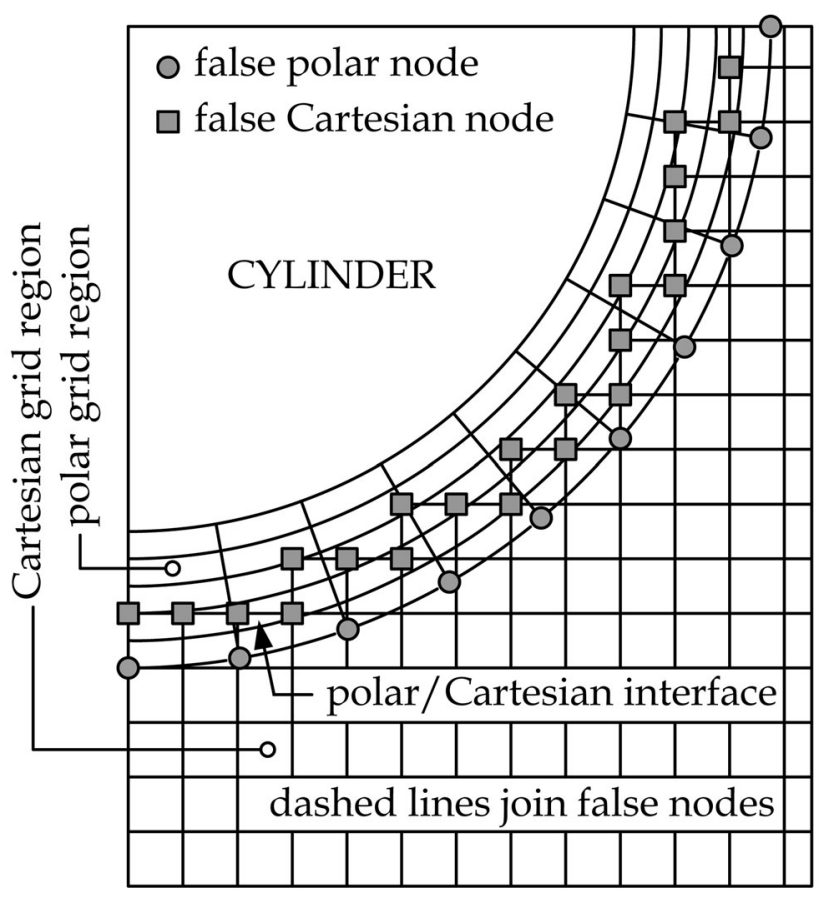

Figure 2. Sketch of the discretization grid system.

Table 1. Grid sensitivity analysis for $W / D=7.5$ and $\Delta \tau$ $=1 \times 10^{-4}$.

\begin{tabular}{|c|c|c|c|c|c|c|}
\hline $\mathrm{Ra}$ & $\mathrm{H} / \mathrm{D}$ & L/D & $\begin{array}{l}\text { Cartesian } \\
\text { mesh size }\end{array}$ & Polar mesh size & $\mathrm{Nu}$ & $\%$ \\
\hline \multirow[t]{4}{*}{$10^{4}$} & 1 & 1.5 & $80 \times 80$ & $30 \times 80$ & 4.98 & - \\
\hline & & & $100 \times 100$ & $35 \times 90$ & 4.90 & -1.61 \\
\hline & & & $120 \times 120$ & $40 \times 100$ & 4.85 & -1.02 \\
\hline & & & $140 \times 140$ & $45 \times 110$ & 4.83 & -0.41 \\
\hline \multirow{4}{*}{$10^{4}$} & 1 & 3 & $80 \times 80$ & $30 \times 80$ & 5.02 & - \\
\hline & & & $100 \times 100$ & $35 \times 90$ & 4.96 & -1.20 \\
\hline & & & $120 \times 120$ & $40 \times 100$ & 4.91 & -1.01 \\
\hline & & & $140 \times 140$ & $45 \times 110$ & 4.89 & -0.41 \\
\hline \multirow[t]{4}{*}{$10^{4}$} & 4 & 3 & $60 \times 60$ & $25 \times 70$ & 4.14 & - \\
\hline & & & $80 \times 80$ & $30 \times 80$ & 4.08 & -1.45 \\
\hline & & & $100 \times 100$ & $35 \times 90$ & 4.03 & -1.23 \\
\hline & & & $120 \times 120$ & $40 \times 100$ & 4.01 & -0.50 \\
\hline \multirow[t]{4}{*}{$10^{6}$} & 4 & 3 & $100 \times 100$ & $35 \times 90$ & 14.06 & - \\
\hline & & & $120 \times 120$ & $40 \times 100$ & 13.86 & -1.42 \\
\hline & & & $140 \times 140$ & $45 \times 110$ & 13.72 & -1.01 \\
\hline & & & $160 \times 160$ & $50 \times 120$ & 13.68 & -0.29 \\
\hline
\end{tabular}

initial conditions stated earlier, is solved through a control-volume formulation of the finite-difference method using an in-house developed computer code. The pressure-velocity coupling is handled using the SIMPLE-C algorithm introduced by Van Doormaal and Raithby [15], which is essentially a more implicit variant of the SIMPLE algorithm developed by Patankar and Spalding [16]. The convective terms are approximated through the QUICK discretization scheme proposed by Leonard [17], whereas a secondorder backward scheme is applied for time integration. According to the geometry of the system, a cylindrical polar grid is employed around each cylinder, whilst a Cartesian grid is used to fill the
Table 2. Time-step sensitivity analysis for $\mathrm{Ra}=10^{4}, \mathrm{~W} /$ $\mathrm{D}=7.5, \mathrm{H} / \mathrm{D}=1$ and $\mathrm{L} / \mathrm{D}=1.5$.

\begin{tabular}{lccccccc}
\hline $\begin{array}{l}\text { Cartesian } \\
\text { mesh size }\end{array}$ & $\begin{array}{c}\text { Polar } \\
\text { mesh size }\end{array}$ & Ra & H/D & L/D & $\Delta \tau$ & Nu & $\%$ \\
\hline $120 \times 120$ & $40 \times 100$ & $10^{4}$ & 1 & 1.5 & $1 \times 10^{-3}$ & 4.99 & - \\
& & & & & $5 \times 10^{-4}$ & 4.90 & -1.80 \\
& & & & & $1 \times 10^{-4}$ & 4.85 & -1.02 \\
& & & & & $5 \times 10^{-5}$ & 4.83 & -0.41 \\
\hline
\end{tabular}

remainder of the integration domain. The polar and Cartesian grids, which are entirely independent of one another, overlap with no attempt of node-matching, their connection being provided by a row of false nodes, in which the values of the dependent variables are calculated by a linear interpolation of their values at the four surrounding real nodes, as depicted in Figure 2 and thoroughly discussed in $[18,19]$. Nonuniform structured grids are used for the discretization of both the polar and the Cartesian grid regions, having a higher concentration of grid nodes near the boundary surfaces, and a relatively lower uniform spacing throughout the remainder interior of the cavity. Conversely, time discretization is chosen uniform.

Starting from the assigned initial fields of the dependent variables, at each time-step the system of the discretized algebraic governing equations is solved iteratively by the way of a line-by-line application of the Thomas algorithm. A standard under-relaxation technique is enforced in all steps of the computational procedure to ensure an adequate convergence. Within each time-step, the spatial numerical solution of the velocity and temperature fields is considered to be converged when the maximum absolute value of the mass source, as well as the relative changes of the dependent variables at any grid-node between two consecutive iterations, are smaller than the pre-specified values of $10^{-6}$ and $10^{-7}$, respectively. As time passes, the dynamic behavior of the system is followed by plotting the phase-space trajectories of the dependent variables at some assigned grid nodes, i.e., by plotting the distributions of the local time-derivatives of the dependent variables versus the variables themselves with time as a parameter, whose attractor may be represented by either a fixed point, a limit cycle, a torus, or a so-called strange attractor, in order to visualize the tendency of the system to reach either a steady-state, a periodic, a quasi-periodic, or a chaotic solution. In addition, the time-distributions of the incoming and outgoing heat transfer rates, as well as their relative difference, are continuously monitored to assess the achievement of an asymptotic solution. 
Table 3. Comparison between the numerical value obtained for $\mathrm{Nu}$ and the corresponding numerical results of Saitoh et al. [20], Wang et al. [21], and Kuehn and Goldstein [22].

\begin{tabular}{|c|c|c|c|c|c|c|c|c|c|}
\hline \multirow{2}{*}{ Ra } & & \multicolumn{7}{|c|}{$\mathrm{Nu}(\theta)$} & \multirow[b]{2}{*}{$\mathrm{Nu}$} \\
\hline & & $\theta=0^{\circ}$ & $30^{\circ}$ & $60^{\circ}$ & $90^{\circ}$ & $120^{\circ}$ & $150^{\circ}$ & $180^{\circ}$ & \\
\hline \multirow[t]{4}{*}{$\overline{10^{3}}$} & Present & 3.789 & 3.755 & 3.640 & 3.376 & 2.841 & 1.958 & 1.210 & 3.013 \\
\hline & Saitoh et al. [20] & 3.813 & 3.772 & 3.640 & 3.374 & 2.866 & 1.975 & 1.218 & 3.024 \\
\hline & Wang et al. [21] & 3.860 & 3.820 & 3.700 & 3.450 & 2.930 & 1.980 & 1.200 & 3.060 \\
\hline & Kuehn and Goldstein [22] & 3.890 & 3.850 & 3.720 & 3.450 & 2.930 & 2.010 & 1.220 & 3.030 \\
\hline \multirow[t]{4}{*}{$10^{4}$} & Present & 5.986 & 5.931 & 5.756 & 5.406 & 4.716 & 3.293 & 1.532 & 4.819 \\
\hline & Saitoh et al. [20] & 5.995 & 5.935 & 5.750 & 5.410 & 4.764 & 3.308 & 1.534 & 4.826 \\
\hline & Wang et al. [21] & 6.030 & 5.980 & 5.800 & 5.560 & 4.870 & 3.320 & 1.500 & 4.860 \\
\hline & Kuehn and Goldstein [22] & 6.240 & 6.190 & 6.010 & 5.640 & 4.820 & 3.140 & 1.460 & 4.940 \\
\hline \multirow[t]{4}{*}{$10^{5}$} & Present & 9.694 & 9.595 & 9.297 & 8.749 & 7.871 & 5.848 & 1.989 & 7.886 \\
\hline & Saitoh et al. [20] & 9.675 & 9.577 & 9.278 & 8.765 & 7.946 & 5.891 & 1.987 & 7.898 \\
\hline & Wang et al. [21] & 9.800 & 9.690 & 9.480 & 8.900 & 8.000 & 5.800 & 1.940 & 7.970 \\
\hline & Kuehn and Goldstein [22] & 10.150 & 10.030 & 9.650 & 9.020 & 7.910 & 5.290 & 1.720 & 8.000 \\
\hline
\end{tabular}

At each time-step, after the spatial convergence is satisfactorily attained, the local Nusselt number of the $\mathrm{i}$-th cylinder, $\left[\mathrm{Nu}_{\theta}(\tau)\right]_{\mathrm{i}}$, is calculated as

$$
\left[N u_{\theta}(\tau)\right]_{i}=-\left[\left.\frac{\partial T(\tau)}{\partial r}\right|_{R, \theta}\right]_{i}(\mathrm{i}=1,2)
$$

where the $r$ and $\theta$ coordinates of the polar system are measured from the center of the cylinder, and anticlockwise from downwards, respectively, and the temperature gradient is evaluated by a second-order temperature profile embracing the wall-node and the two adjacent fluid-nodes.

Hence, the corresponding average Nusselt number of the $\mathrm{i}$-th cylinder at time $\tau,[\mathrm{Nu}(\tau)]_{\mathrm{i}}$, is calculated with the expression

$$
[N u(\tau)]_{i}=\frac{1}{2 \pi}\left[\int_{0}^{2 \pi}-\left.\frac{\partial T(\tau)}{\partial r}\right|_{R, \theta} d \theta\right]_{i}(\mathrm{i}=1,2)
$$

in which the integral is computed numerically by means of the trapezoidal rule.

Time integration is stopped once an asymptotic solution, either stationary or periodic, is reached.

When a steady-state solution is achieved, the Nusselt number of the i-th cylinder coincides with the last value computed for $[\mathrm{Nu}(\tau)]_{\mathrm{i}}$ :

$$
N u_{i}=\left.[N u(\tau)]_{i}\right|_{\tau \rightarrow \infty} \quad(\mathrm{i}=1,2)
$$

Conversely, when a periodic solution is attained, the Nusselt number $\mathrm{Nu}_{\mathrm{i}}$ is evaluated as

$$
N u_{i}=\frac{1}{\Omega} \int_{0}^{\Omega}[N u(\tau)]_{i} d \tau \quad(\mathrm{i}=1,2)
$$

where $\Omega$ is the dimensionless period of oscillation computed by the solution algorithm.

The heat transfer performance of the whole system is then calculated as the arithmetic mean of the average Nusselt numbers of both cylinders, that is,

\begin{tabular}{|c|c|c|c|c|c|c|}
\hline & \multicolumn{6}{|c|}{$\mathrm{Ra}$} \\
\hline & $10^{2}$ & $10^{3}$ & $10^{4}$ & $10^{5}$ & $10^{6}$ & $2 \times 10^{6}$ \\
\hline Present & 2.340 & 3.450 & 5.700 & 9.240 & 15.889 & 18.713 \\
\hline Raithby and Hollands [23] & 2.347 & 3.552 & 5.645 & 9.330 & 15.856 & 18.674 \\
\hline Kuehn and Goldstein [24] & 2.369 & 3.589 & 5.711 & 9.445 & 16.062 & 18.923 \\
\hline
\end{tabular}

Table 4. Comparison between the numerical value obtained for Nu and the correlations of Raithby and Hollands [23], and Kuehn and Goldstein [24].

Numerical tests on the dependence of the obtained results on the mesh spacing and time stepping have been methodically performed for several combinations of the four controlling parameters, namely, Ra, W/D, $\mathrm{L} / \mathrm{D}$, and $\mathrm{H} / \mathrm{D}$. Accordingly, the discretization grids and time-steps used for computations are chosen in such a way that further refinements do not produce noticeable modifications either in the heat transfer rates or in the flow fields, with percentage changes smaller than the pre-established accuracy of $1 \%$. The typical number of nodal points of the polar and Cartesian discretization grids used for simulations lie in the ranges between $40 \times 100$ and $50 \times 120$, and between $120 \times 120$ and $140 \times 140$, respectively. Moreover, typical dimensionless time-steps used for simulations lie in the range between $10^{-4}$ and $10^{-3}$. Selected results of the grid-size and time-stepping sensitivity analysis are presented in Tables 1 and 2 . Finally, with the scope to validate the numerical code and the composite-grid discretization scheme used in the present study, a couple of tests have been carried out. In the first test, the local and average Nusselt numbers computed at several Rayleigh numbers for a single cylinder suspended in air have been compared with the corresponding benchmark numerical results of Saitoh et al. [20], as shown in Table 3, where the numerical results of Wang et al. [21], and Kuehn and Goldstein [22], are also reported for further 


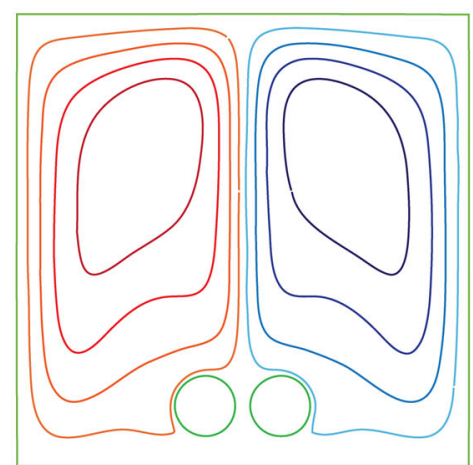

(a)

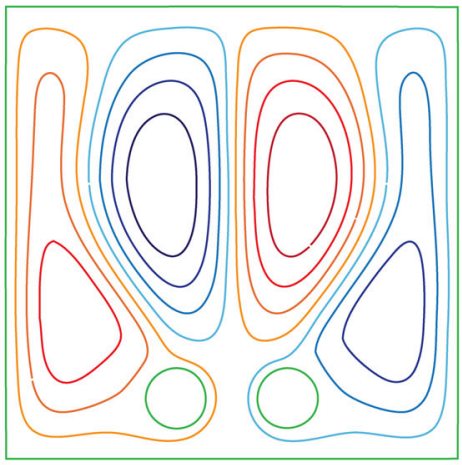

(d)

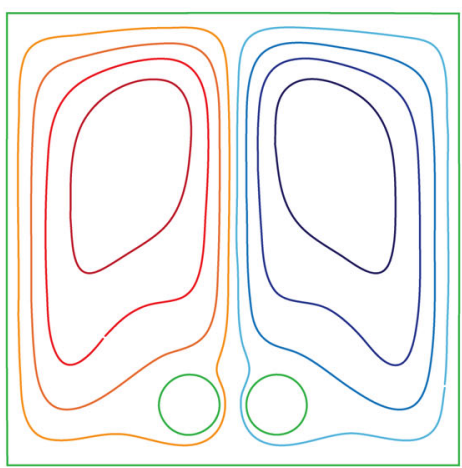

(b)

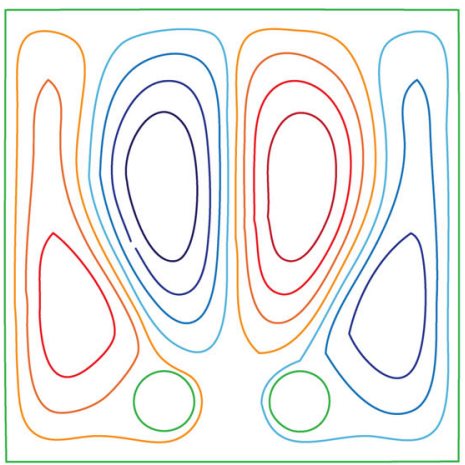

(e)

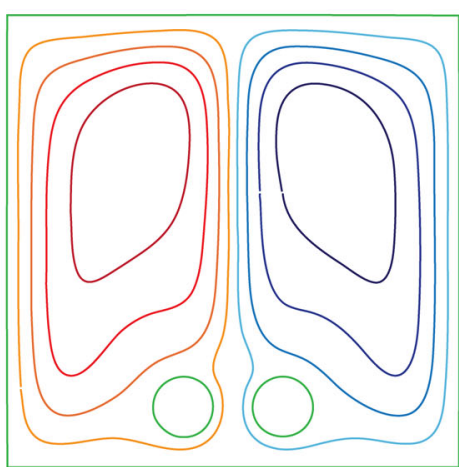

(c)

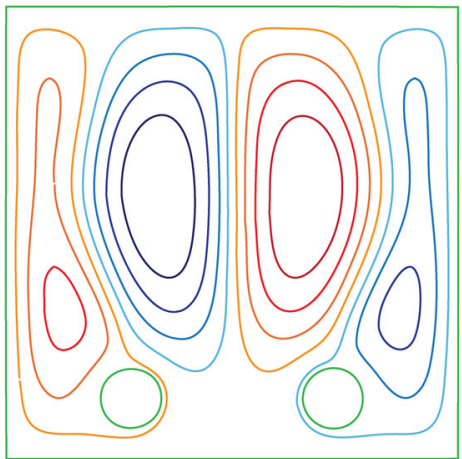

(f)

Figure 3. Steady-state streamline contours for $\mathrm{Ra}=10^{4}, \mathrm{~W} / \mathrm{D}=7.5, \mathrm{H} / \mathrm{D}=1$ and $\mathrm{L} / \mathrm{D}=1.25,1.55,1.75,1.85,2.25$ and 3.35 .

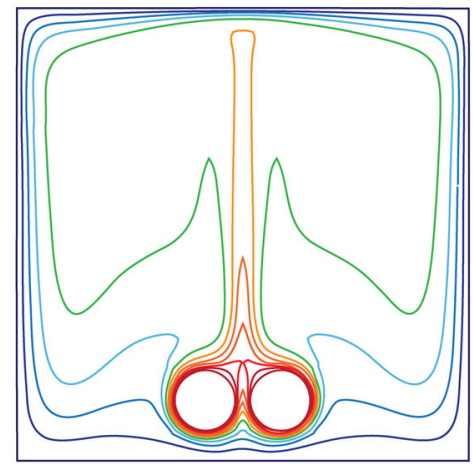

(a)

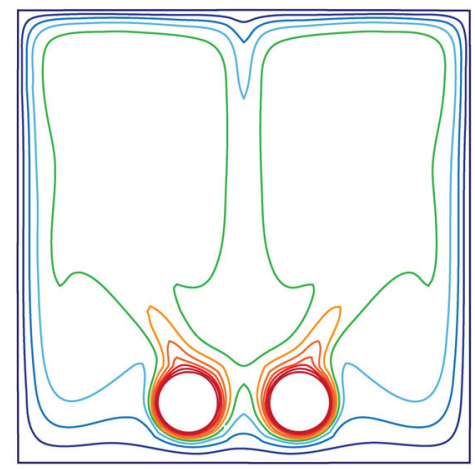

(d)

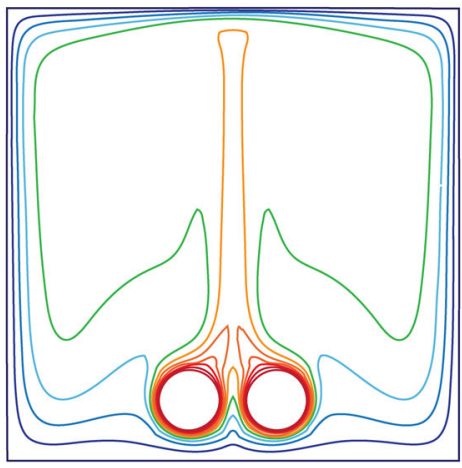

(b)

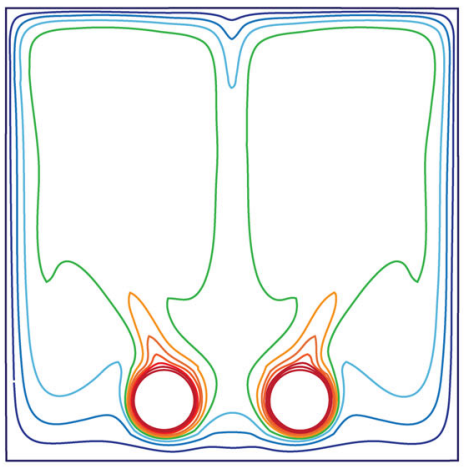

(e)

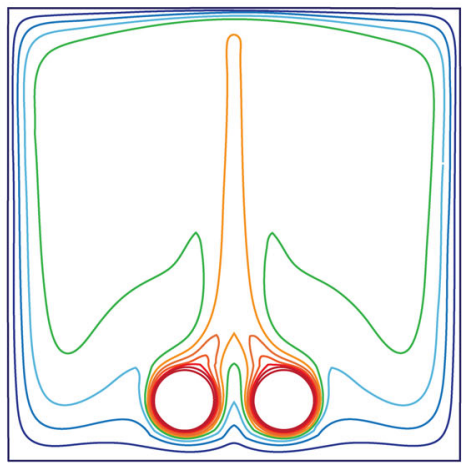

(c)

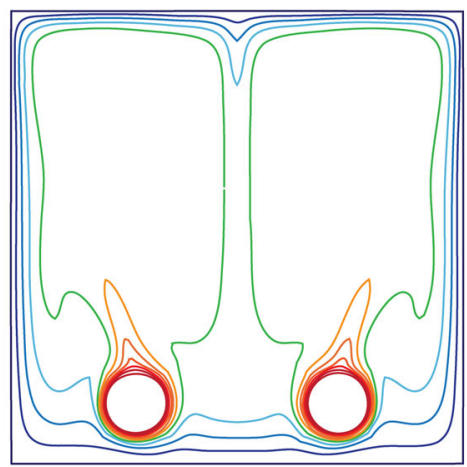

(f)

Figure 4. Steady-state isotherm contours for $\mathrm{Ra}=10^{4}, \mathrm{~W} / \mathrm{D}=7.5, \mathrm{H} / \mathrm{D}=1$ and $\mathrm{L} / \mathrm{D}=1.25,1.55,1.75,1.85,2.25$ and 3.35 . 


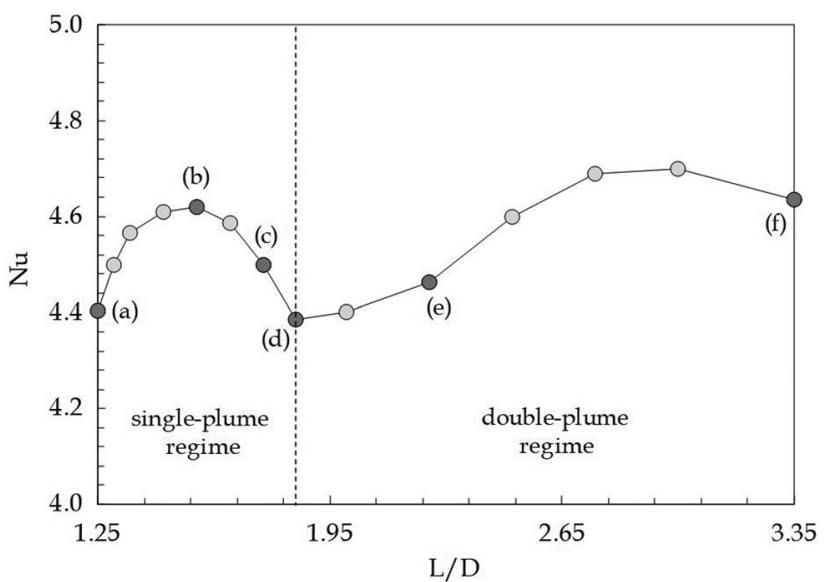

Figure 5. Distribution of $\mathrm{Nu}$ vs. L/D for $\mathrm{Ra}=10^{4}, \mathrm{~W} / \mathrm{D}=7.5$ and $H / D=1$.

comparison. In the second test, the average Nusselt numbers computed at several Rayleigh numbers for a single cylinder suspended in water have been compared with the data obtained using some of the most prominent correlations for free convection heat transfer from a single cylinder available in the literature, i.e., those by Raithby and Hollands [23], and Kuehn and Goldstein [24], as shown in Table 4. Further details are discussed at length in $[18,19]$.

\section{Results and discussion}

Numerical simulations are performed for $\operatorname{Pr}=7$, which corresponds to water, and different values of (a) the Rayleigh number $\mathrm{Ra}$ in the range between $10^{3}$ and $10^{6}$, (b) the dimensionless cavity width W/D in the range between 4 and 10, (c) the dimensionless centerto-center cylinder spacing $\mathrm{L} / \mathrm{D}$ in the range between 1.25 and $(\mathrm{W} / \mathrm{D}-1.25)$, and (d) the dimensionless distance of the cylinder axis from the bottom of the enclosure $\mathrm{H} / \mathrm{D}$ in the range between 1 and (W/D - 1).

Typical local results are reported in Figures 3 and 4 , in which steady-state streamline and isotherm contours, relative to six different cylinder spacings, are plotted for $\mathrm{Ra}=10^{4}$ and $\mathrm{H} / \mathrm{D}=1$. It is apparent that at the lower investigated values of the cylinder spacing the flow structure consists of two counter-rotating, kidney-shaped cells originating from the rise of the hot fluid above the pair of heated cylinders and the fall of two streams of cold fluid along the cooled sidewalls. The related temperature distribution is featured by a thermal plume emerging from the top of the pair of cylinders, as it were generated by a single source, and three boundary layers adjacent to the sides and the top wall of the cavity. At larger cylinder spacings the flow field consists of a primary circulation

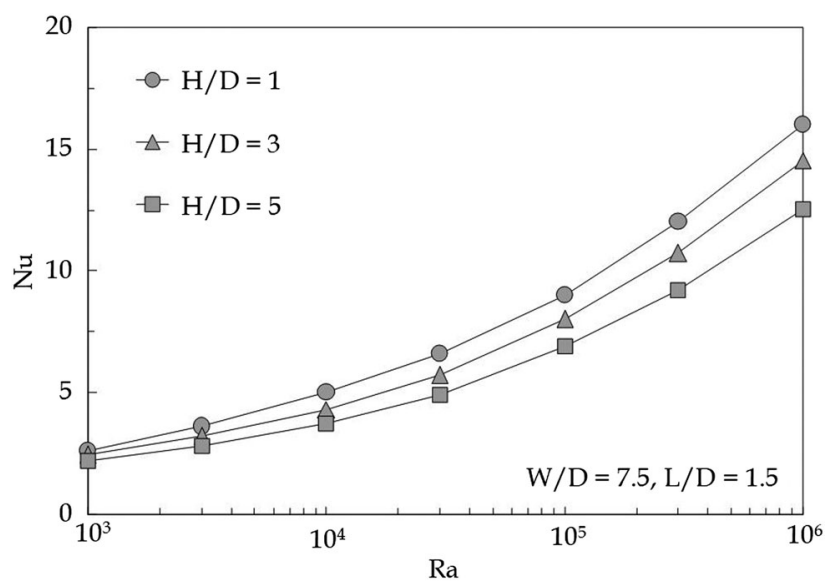

Figure 6. Distributions of Nu vs. Ra $=10^{4}$, for $\mathrm{W} / \mathrm{D}=7.5$ and $\mathrm{L} / \mathrm{D}=1.5$, using $\mathrm{H} / \mathrm{D}$ as a parameter.

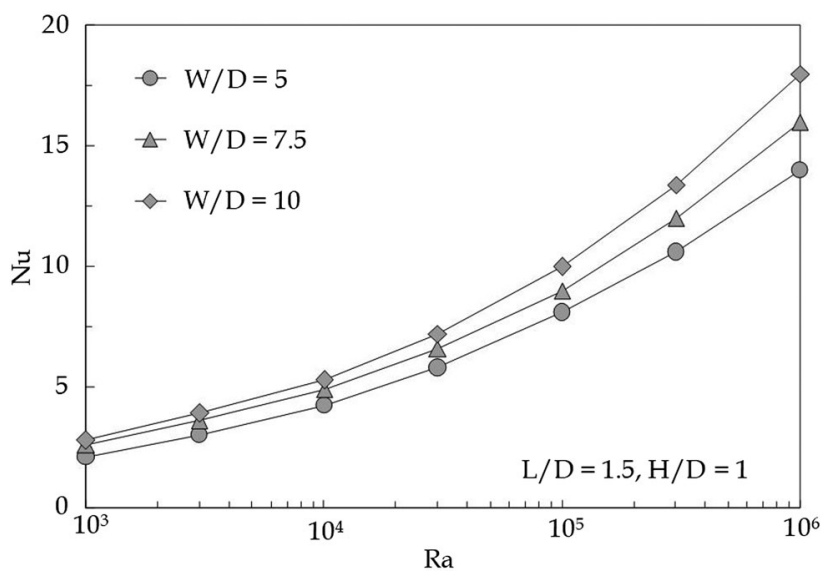

Figure 7. Distributions of $\mathrm{Nu}$ vs. $\mathrm{Ra}=10^{4}$, for $\mathrm{L} / \mathrm{D}=1.5$ and $H / D=1$, using W/D as a parameter.

occurring between each cylinder and the adjacent sidewall, due to the rise of the hot fluid above the heated cylinder and its fall along the cooled sidewall, and a secondary circulation in the middle portion of the cavity, driven by the plumes arising from any cylinder and the column of cold fluid descending from the top wall. According to this description, two different regimes can be distinguished, depending on the fact that the heat and fluid flow inside the cavity takes origin either from the rise of a single plume or from the rise of two separate plumes, as clearly reflected by the distribution of the average Nusselt number plotted in Figure 5.

As expected, the average Nusselt number increases with increasing the cylinder spacing $\mathrm{L} / \mathrm{D}$ up to a point, which is due to the increased flow rate drawn between the cylinders by the "chimney effect". As L/D is further increased, $\mathrm{Nu}$ decreases due to the velocity decrease of the liquid rising between the cylinders, yet such a diminution ends when the transition from the 

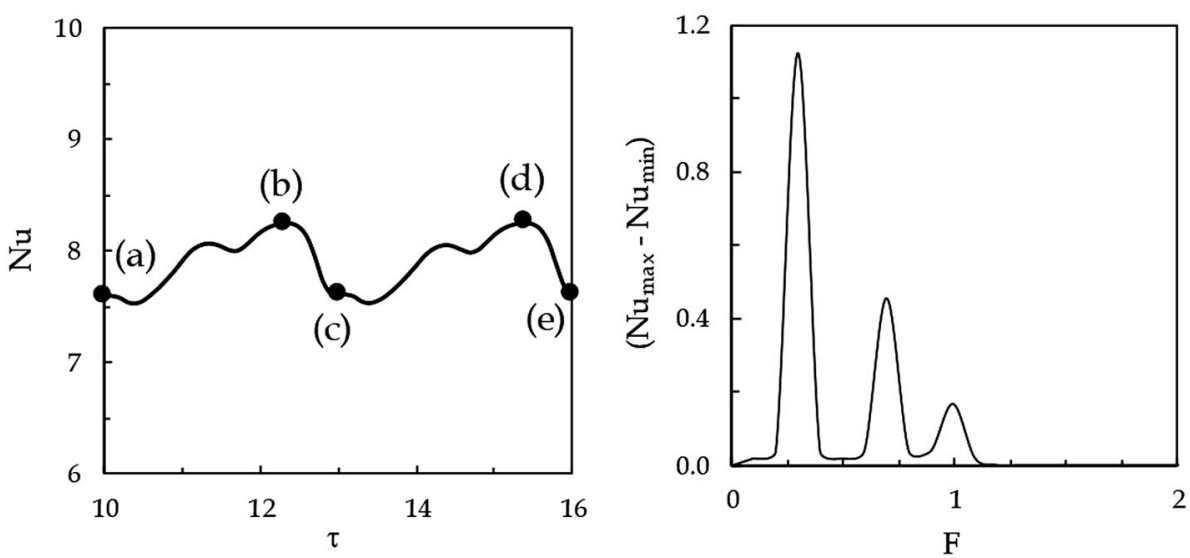

Figure 8. Distributions of $\mathrm{Nu}$ vs. $\tau$ and related asymptotic Fourier frequency spectrum of $\left(\mathrm{Nu}_{\max }-\mathrm{Nu}_{\min }\right)$ for $\mathrm{Ra}=10^{5}, \mathrm{~W} / \mathrm{D}=7.5$, $\mathrm{H} / \mathrm{D}=1$ and $\mathrm{L} / \mathrm{D}=5.35$.

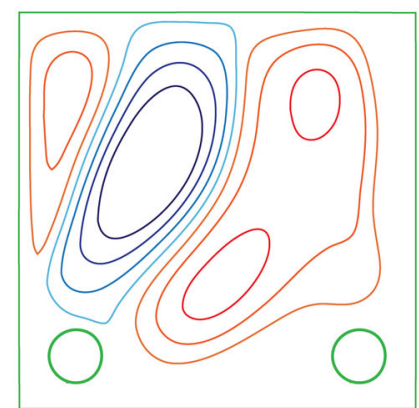

(a)

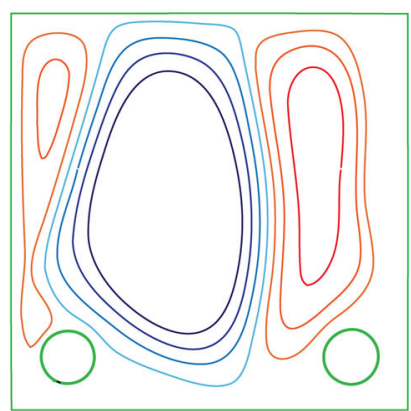

(b)

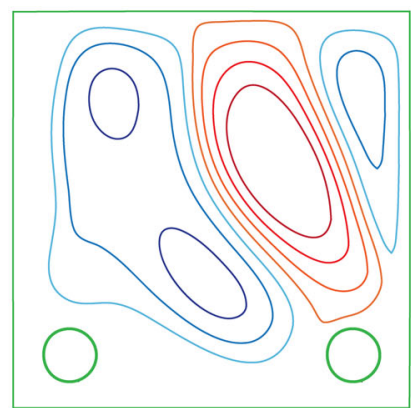

(c)

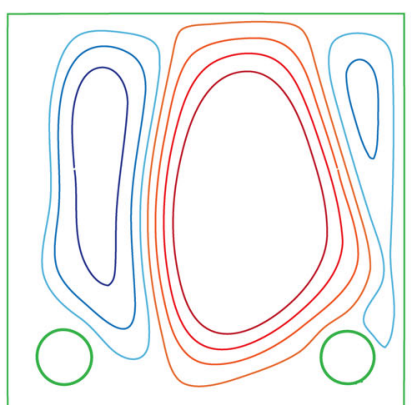

(d)

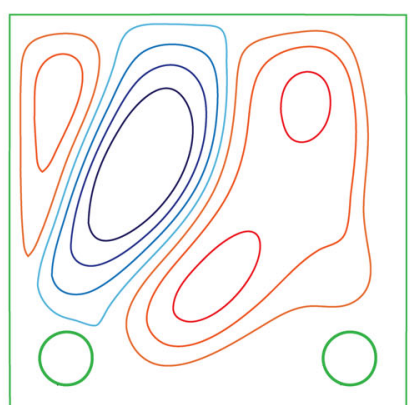

(e)

Figure 9. Asymptotic time evolution of the streamline contours during one period of oscillation for $R a=10^{5}, W / D=7.5, H / D=1$ and $\mathrm{L} / \mathrm{D}=5.35$.

single-plume regime to the double-plume regime occurs, which is due to the role played by the cold sides in determining a change in the flow pattern. From this point on, any increase of L/D implies an increase of $\mathrm{Nu}$, due to the more and more marked interaction occurring between the plumes and the sides of the cavity, up to a point, over which the vicinity of the cylinders to the cooled walls has a direct effect on the motion intensity of the fluid flowing between any cylinder and the adjacent sidewall. Similar distributions of $\mathrm{Nu}$ vs. $\mathrm{L} / \mathrm{D}$ are found for most of the investigated configurations.
As regards the dimensionless cylinder elevation $\mathrm{H} /$ $\mathrm{D}$, the dimensionless cavity size $\mathrm{W} / \mathrm{D}$ and the Rayleigh number $\mathrm{Ra}$, their effects on the heat transfer performance of the system are pointed out in Figures 6 and 7, showing that $\mathrm{Nu}$, besides increasing with $\mathrm{Ra}$ due to the higher buoyancy, decreases as H/D is increased and $\mathrm{W} / \mathrm{D}$ is decreased as a consequence of the decrease of the fluid motion strength.

Finally, it seems worth noticing that when the cylinders are located in the close vicinity of the cavity sides, the interactions occurring between the thermal plume generated by any cylinder and the adjacent 


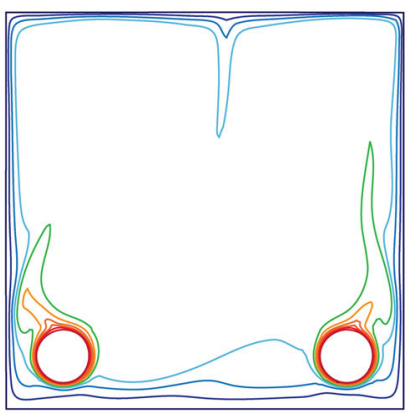

(a)

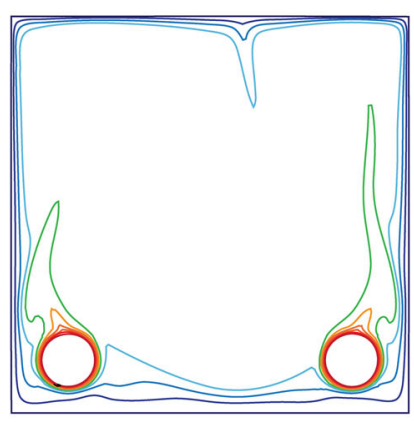

(b)

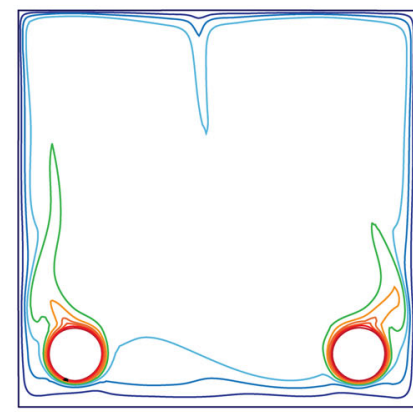

(c)

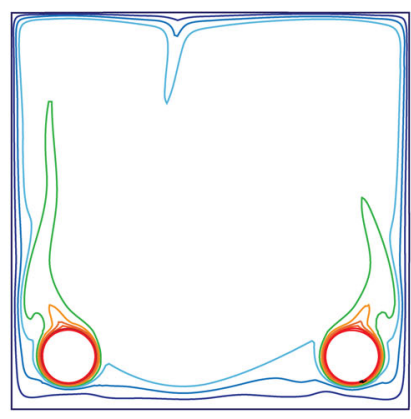

(d)

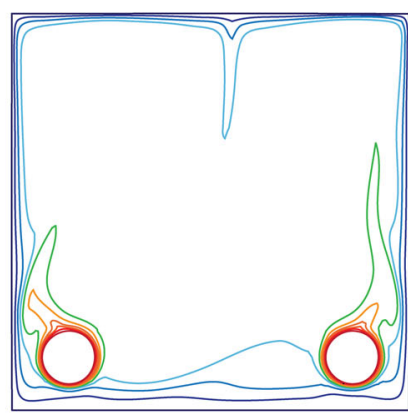

(e)

Figure 10. Asymptotic time evolution of the isotherm contours during one period of oscillation for $R a=10^{5}, W / D=7.5, H / D=1$ and $\mathrm{L} / \mathrm{D}=5.35$.

cooled sidewall give rise to periodic oscillations, as e.g. displayed in Figure 8, in which the asymptotic time-distribution of the average Nusselt number $\mathrm{Nu}$ along one period of oscillation and the related Fourier frequency spectrum of the heat transfer performance, displayed in terms of $\left(\mathrm{Nu}_{\max }-\mathrm{Nu}_{\min }\right)$ vs. $\mathrm{F}$, where $\mathrm{F}$ is the dimensionless frequency of oscillation given by the reciprocal of the dimensionless period of oscillation $\Omega$, are reported for $\mathrm{Ra}=10^{5}, \mathrm{~W} / \mathrm{D}=7.5$, $\mathrm{H} / \mathrm{D}=1$ and $\mathrm{L} / \mathrm{D}=5.25$. The corresponding asymptotic time-evolutions of the streamline and isotherm contour plots are documented in Figures 9 and 10, respectively, by the way of five snapshots covering the full period of oscillation.

\section{Conclusions}

Laminar natural convection from a pair of heated horizontal cylinders set side by side in a water-filled cooled square cavity has been studied numerically by means of a control-volume formulation of the finitedifference method based on the SIMPLE-C algorithm.

The main results obtained may be summarized as follows:

a. two heat and fluid flow regimes, conventionally named single-plume regime and double-plume regime, can be distinguished, according as the cylinders are located close to each other or at some distance between them such that the sidewall effect becomes meaningful;

b. in line of principle, each of these regimes is characterized by the existence of an optimum cylinder spacing for maximum heat transfer performance;

c. the average Nusselt number is found to increase when the Rayleigh number is increased, as well as the distance of the cylinders from the bottom of the cavity is decreased and the cavity size is increased;

d. as a consequence of the interactions occurring between the thermal plume generated by any cylinder and the adjacent cooled sidewall, a periodic flow arises when the cylinders are located in the close vicinity of the sides of the enclosure.

\section{Notes on contributors}

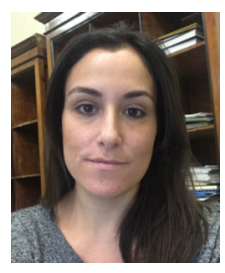

Marta Cianfrini is a post-doctoral student at Roma Tre University of Rome, Italy. She received her M.S. degree in Biomedical Engineering in 2009 and her Ph.D. in Energetics in 2014 from Sapienza University of Rome, Italy. Her main research interests include heat transfer and convection of pure fluids and nanofluids. She has coauthored more than 10 papers in archival journals and conference proceedings. 


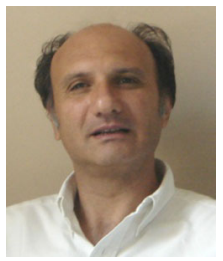

Massimo Corcione is a Full Professor of Thermal Sciences and HVAC Systems at Sapienza University of Rome, Italy. He received his M.S. degree in Mechanical Engineering in 1990 and his Ph.D. in Thermophysical Properties of Materials in 1995 from Sapienza University of Rome, Italy. His current research interests include convection of pure fluids and mixtures, heat transfer in nanofluids, and optimal design of HVAC systems. He is a member of ANS (American Nano Society), ASME (American Society of Mechanical Engineers) and UIT (Unione Italiana di Termofluidodinamica). He has authored or coauthored more than 130 refereed journal and conference publications, besides contributing to a number of books.

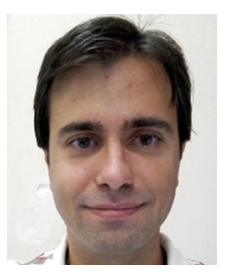

Luca Cretara is a Post Doc at "Sapienza" University of Rome, Italy. He received his M.S. degree in energetic engineering in 2012 and his Ph.D. in Energy and Environment in 2016 from "Sapienza" University of Rome, Italy. His research activity mainly concerns nuclear power plants analysis and modeling, with interest in neutron transport and reactor physics studies. He has coauthored 7 works including papers in archival journals, technical reports and conference presentations.

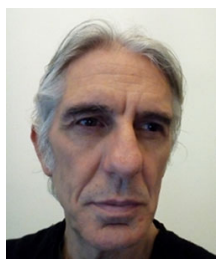

Massimo Frullini is a researcher at "Sapienza" University of Rome, Italy since 1990. He received his M.S. degree in nuclear engineering in 1987 from "Sapienza" University of Rome, Italy. His main research activities include coupling between neutron transport models and heat transfer performance in water or liquid metal cooled nuclear reactors and optimal design of heat exchangers systems used in nuclear power plants. $\mathrm{He}$ has authored or coauthored more than 30 papers in archival journals and conference proceedings.

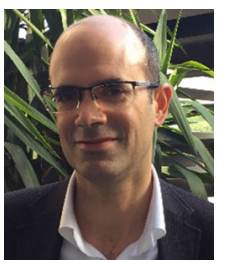

Emanuele Habib received M.S. degree in Mechanical Engineering in 2002 and Ph.D. in Applied Physics in 2007. In 2011, he joined the Department of Astronautics, Electrical and Energy Engineering of the Sapienza University of Rome where he is currently an Assistant Professor of Applied Physics. His main research fields are natural convection heat transfer, heat transfer of buildings and energy performance of HVAC systems.

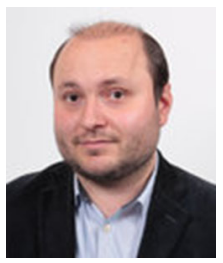

Paweł Ocłoń, works as an Associate Professor in the Institute of Thermal Power Engineering, Faculty of Mechanical Engineering at Cracow University of Technology. His research area covers the heat transfer and energy engineering including numerical simulation of heat transfer in underground power cable systems and heating networks, numerical simulation of finand-tube heat exchangers heat transfer and fluid flow, modeling of combined heat and power plants, modeling of heat and fluid flow processes in supercritical boilers. He also performs experimental works on heat exchangers and underground power cable systems. He has published over $30 \mathrm{SCI}$ papers in highly ranked journals in heat transfer and energy engineering.

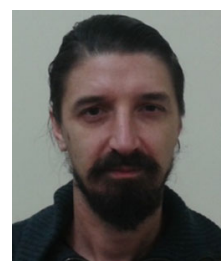

Alessandro Quintino is an Assistant Professor of Thermal Sciences at "Sapienza" University of Rome, Italy. He received his M.S. degree in Aeronautical Engineering in 2000 and his Ph.D. in Thermal Sciences in 2011 from Sapienza University of Rome, Italy. His main research interests include convection of pure fluids and mixtures, heat transfer in nanofluids, and optimal design of HVAC systems. He has authored or coauthored more than 40 papers in archival journals and conference proceedings.

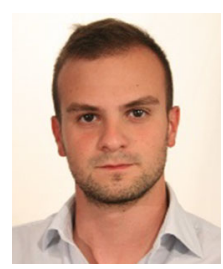

Vincenzo Andrea Spena is a $\mathrm{PhD}$ student at "Sapienza" University of Rome, Italy. He received his M.S. degree in Mechanical Engineering in 2017 and he is at the second year of his doctorate in Energy and Environment. His main research interests include convection of pure fluids and mixtures and heat transfer in nanofluids. $\mathrm{He}$ has authored or coauthored 6 papers in archival journals and conference proceedings.

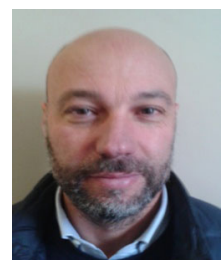

Andrea Vallati is an Assistant Professor of Thermal Sciences at "Sapienza" University of Rome, Italy. He received his M.S. degree in Mechanical Engineering in 1997 and his Ph.D. in Thermal Sciences in 2001 from "Sapienza" University of Rome, Italy. His main research interests include heat transfer and energy systems. He has authored or coauthored more than 70 refereed journal and conference publications.

\section{References}

1. F. P. Incropera, and M. A. Yaghoubi, "Buoyancy driven flow originating from heated cylinders submerged in a finite water layer," Int. J. Heat Mass Transfer, vol. 23, no. 3, pp. 269-278, 1980. DOI: 10. 1016/0017-9310(80)90114-3.

2. J. P. Kuehner, J. R. Pflug, A. Tessier, Jr., A. M. Hamed, and F. J. Marin, "Velocity measurements in the free convection flow above a heated horizontal cylinder," Int. J. Heat Mass Transfer, vol. 55, no. 17-18, pp. 4711-4723, 2012. DOI: 10.1016/j.ijheatmasstransfer.2012.04.031.

3. D. Fiscaletti, D. Angeli, L. Tarozzi, and G. S. Barozzi, "Buoyancy-induced transitional flows around an enclosed horizontal cylinder: An experiment," Int. J. Heat Mass Transfer, vol. 58, no. 1-2, pp. 619-631, 2013. DOI: 10.1016/j.ijheatmasstransfer.2012.11.039. 
4. O. Reymond, D. B. Murray, and T. S. O'Donovan, "Natural convection heat transfer from two horizontal cylinders," Exp. Thermal Fluid Sci., vol. 32, no. 8, pp. 1702-1709, 2008. DOI: 10.1016/j.expthermflusci.2008. 06.005 .

5. T. Persoons, I. M. O'Gorman, D. B. Donoghue, G. Byrne, and D. B. Murray, "Natural convection heat transfer and fluid dynamics for a pair of vertically aligned isothermal horizontal cylinders," Int. J. Heat Mass Transfer, vol. 54, no. 25-26, pp. 5163-5172, 2011. DOI: 10.1016/j.ijheatmasstransfer.2011.08.033.

6. M. S. Chae, and B. J. Chung, "Effect of pitch-to-diameter ratio on the natural convection heat transfer of two vertically aligned horizontal cylinders," Chem. Eng. Sci., vol. 66, no. 21, pp. 5321-5329, 2011. DOI: 10.1016/j.ces.2011.07.021.

7. S. Grafsrønningen, and A. Jensen, "Natural convection heat transfer from two horizontal cylinders at high Rayleigh numbers," Int. J. Heat Mass Transfer, vol. 55, no. 21-22, pp. 5552-5564, 2012. DOI: $10.1016 /$ j. ijheatmasstransfer.2012.05.033.

8. S. Grafsrønningen, and A. Jensen, "Natural convection heat transfer from three vertically arranged horizontal cylinders with dissimilar separation distance at moderately high Rayleigh numbers," Int. J. Heat Mass Transfer, vol. 57, no. 2, pp. 519-527, 2013. DOI: 10. 1016/j.ijheatmasstransfer.2012.10.076.

9. R. Shyam, C. Sasmal, and R. P. Chhabra, "Natural convection heat transfer from two vertically aligned circular cylinders in power-law fluids," Int. J. Heat Mass Transfer, vol. 64, pp. 1127-1152, 2013. DOI: 10. 1016/j.ijheatmasstransfer.2013.05.052.

10. J. H. Heo, M. S. Chae, and B. J. Chung, "Influences of vertical and horizontal pitches on the natural convection of two staggered cylinders," Int. J. Heat Mass Transfer, vol. 57, no. 1, pp. 1-8, 2013. DOI: 10.1016/j. ijheatmasstransfer.2012.10.001.

11. J. H. Heo, and B. J. Chung, "Natural convection of two staggered cylinders for various Prandtl numbers and vertical and horizontal pitches," Heat Mass Transfer, vol. 50, no. 6, pp. 769-777, 2014. DOI: 10. 1007/s00231-013-1285-x.

12. A. K. Baranwal, and R. Chhabra, "Effect of Prandtl number on free convection from two cylinders in a square enclosure," Heat Transfer Eng., vol. 37, no. 6, pp. 545-556, 2016. DOI: 10.1080/01457632.2015. 1060761.

13. A. K. Baranwal, and R. Chhabra, "Free convection in confined power-law fluids from two side-by-side cylinders in a square enclosure," Heat Transfer Eng., vol. 37, no. 18, pp. 1521-1537, 2016. DOI: 10.1080/ 01457632.2016.1151296.

14. A. K. Baranwal, and R. Chhabra, "Effect of fluid yield stress on natural convection from horizontal cylinders in a square enclosure," Heat Transfer Eng., vol. 38, no. 6, pp. 557-577, 2017. DOI: 10.1080/01457632. 2016.1200373.

15. J. P. Van Doormaal, and G. D. Raithby, "Enhancements of the simple method for predicting incompressible fluid flows," Num. Heat Transfer, vol. 7, no. 2, pp. 147-163, 1984. DOI: 10.1080/ 01495728408961817.

16. S. V. Patankar, and D. B. Spalding, "A calculation procedure for heat, mass and momentum transfer in three-dimensional parabolic flows," Int. J. Heat Mass Transfer, vol. 15, no. 10, pp. 1787-1797, 1972. DOI: 10.1016/0017-9310(72)90054-3.

17. B. P. Leonard, "A stable and accurate convective modelling procedure based on quadratic upstream interpolation," Comp. Meth. Appl. Mech. Eng., vol. 19, no. 1 , pp. 59-78, 1979. DOI: 10.1016/00457825(79)90034-3.

18. M. Corcione, "Correlating equations for free convection heat transfer from horizontal isothermal cylinders set in a vertical array," Int. J. Heat Mass Transfer, vol. 48 , no. 17 , pp. $3660-3673$, 2005. DOI: $10.1016 /$ j.ijheatmasstransfer.2005.01.010.

19. M. Corcione, "Interactive free convection from a pair of vertical tube-arrays at moderate Rayleigh numbers," Int. J. Heat Mass Transfer, vol. 50, no. 5-6, pp. 1061-1074, 2007. DOI: 10.1016/j.ijheatmasstransfer. 2006.07.034.

20. T. Saitoh, T. Sajiki, and K. Maruhara, "Bench mark solutions to natural convection heat transfer problem around a horizontal circular cylinder," Int. J. Heat Mass Transfer, vol. 36, no. 5, pp. 1251-1259, 1993. DOI: 10.1016/S0017-9310(05)80094-8.

21. P. Wang, R. Kahawita, and T. H. Nguyen, "Numerical computation of the natural convection flow about a horizontal cylinder using splines," Numer. Heat Transfer, vol. 17, no. 2, pp. 191-215, 1990. DOI: 10. 1080/10407789008944739.

22. T. H. Kuehn, and R. J. Goldstein, "Numerical solution to the Navier-Stokes equations for laminar natural convection about a horizontal isothermal circular cylinder," Int. J. Heat Mass Transfer, vol. 23, no. 7, pp. 971-979, 1980. DOI: 10.1016/0017-9310(80)90071-X.

23. G. D. Raithby, and K. G. T. Hollands, "Laminar and turbulent free convection from elliptic cylinders with a vertical plate and horizontal circular cylinder as special cases," J. Heat Transfer, vol. 98, no. 1, pp. 72-80, 1976. DOI: $10.1115 / 1.3450473$.

24. T. H. Kuehn, and R. J. Goldstein, "Correlating equations for natural convection heat transfer between horizontal circular cylinders," Int. J. Heat Mass Transfer, vol. 19, no. 10, pp. 1127-1134, 1976. DOI: 10.1016/0017-9310(76)90145-9. 